\title{
STRICA, a novel Drosophila melanogaster caspase with an unusual serine/threonine-rich prodomain, interacts with DIAP1 and DIAP2
}

\author{
J Doumanis ${ }^{1}$, L Quinn ${ }^{2}$, H Richardson ${ }^{2}$ and S Kumar*,1 \\ 1 Hanson Centre for Cancer Research, Institute of Medical and Veterinary \\ Science, P0 Box 14, Rundle Mall, Adelaide, SA 5000, Australia \\ 2 Peter MacCallum Cancer Institute, Locked Bag 1, A'Beckett Street, Melbourne, \\ Vic. 8006, Australia \\ * Corresponding author: S Kumar, Hanson Centre for Cancer Research, Institute \\ of Medical and Veterinary Science, PO Box 14, Rundle Mall, Adelaide, SA 5000, \\ Australia. Tel: +61-8-8222-3738; Fax: +61-8-8222-3139; \\ E-mail: sharad.kumar@imvs.sa.gov.au
}

Received 5.1.01; revised 20.2.01; accepted 20.2.01

Edited by S Martin

\begin{abstract}
The recently published genome sequence of Drosophila melanogaster predicts seven caspases in the fly. Five of these caspases have been previously characterised. Here, we describe the Drosophila caspase, STRICA. STRICA is a caspase with a long amino-terminal prodomain that lacks any caspase recruitment domain or death effector domain. Instead, the prodomain of STRICA consists of unique serine/ threonine stretches. Low levels of strica expression were detected in embryos, larvae, pupae and adult animals. STRICA is a cytoplasmic protein that, upon overexpression, caused apoptosis in cultured Drosophila SL2 cells that was partially suppressed by DIAP1. Interestingly, unlike other fly caspases, STRICA showed physical association with DIAP2, in cotransfection experiments. These results suggest that STRICA may have a unique cellular function. Cell Death and Differentiation (2001) 8, 387-394.
\end{abstract}

Keywords: apoptosis; caspase; prodomain; IAPs

Abbreviations: CARD, caspase recruitment domain; DED, death effector domain; IAP, inhibitor of apoptosis

\section{Introduction}

Programmed cell death in metazoans is mediated by a family of cysteine proteases termed caspases, which cleave their substrates following an aspartate residue. ${ }^{1-5}$ To date 14 caspases have been cloned in mammals. ${ }^{1-4}$ Gene targeting studies in mouse suggest that some caspases play spatially restricted roles in apoptosis, whereas others seem mainly involved in the processing and activation of proinflammatory cytokines. ${ }^{6}$ In Drosophila melanogaster there are seven caspases as predicted by the sequenced Drosophila genome, five of which, DCP-1, DREDD/DCP-2, DRICE,
DRONC and DECAY have been previously published, ${ }^{7-12}$ whereas the other two, DAMM and STRICA, have not been characterised. ${ }^{5}$

Caspases are classified into two broad groups, based on the presence or absence of a long amino-terminal prodomain. The prodomains in some caspases contain specific protein-protein interaction motifs that appear to function in caspase activation either by mediating procaspase oligomerisation, or interaction of the caspase precursor with adaptor molecules leading to caspase autoprocessing. ${ }^{13,14}$ Among the published Drosophila caspases, DREDD and DRONC contain long prodomains carrying death effector domains (DEDs) and a caspase recruitment domain (CARD), respectively. ${ }^{5}$ In the case of mammalian caspase-9, interaction with the adaptor molecule Apaf-1 occurs through the CARD present in each protein. ${ }^{15,16}$ Caspase-8 also associates with an adaptor molecule, FADD via DED interactions. ${ }^{17}$ It is likely that DRONC and DREDD are functional homologues of caspase- 9 and caspase- 8 respectively, as evident by the ability of DRONC to associate with the Drosophila Apaf-1 homologue Dark, ${ }^{18-20}$ and of DREDD with Drosophila FADD, dFADD. ${ }^{21}$ DCP-1, DRICE, DECAY and DAMM lack long prodomains and are thus similar to downstream effector caspases in mammals. ${ }^{5} d c p-1$ mutation results in larval lethality and melanotic tumors. ${ }^{7}$ Additionally, DCP-1 is required for Drosophila oogenesis, as $d c p-1$ mutants show a defect in transfer of nurse cell cytoplasmic contents to developing oocytes. ${ }^{22}$ Heterozygosity at the dredd locus suppresses cell death induced by ectopic expression of rpr, hid and grim in transgenic models, ${ }^{9}$ indicating that DREDD concentration may be a rate limiting step in this pathway. In addition to its function in apoptosis, DREDD also plays a key role in the innate immune response. ${ }^{23-25}$

Several lines of evidence suggest that DRONC is a key upstream caspase in the fly cell death machinery. dronc mRNA is upregulated several fold by ecdysone in larval salivary glands and midgut prior to histolysis of these tissues. ${ }^{11}$ Furthermore, the heterozygosity at the dronc locus or the expression of a catalytically inactive DRONC mutant suppress the eye phenotype caused by rpr, grim and hid, consistent with the idea that DRONC functions in the RPR, GRIM and HID pathway. ${ }^{18,26,27}$ Furthermore, loss of dronc function in early Drosophila embryos using the RNA interference technique results in a block of apoptosis, indicating that DRONC is required for programmed cell death during embryogenesis. ${ }^{18}$ In vitro antibody depletion experiments suggest that DRICE is required for apoptotic activity in a Drosophila cell line. ${ }^{28}$ Furthermore, DRICE physically associates with DRONC and can be processed by DRONC, suggesting that it may be downstream of DRONC in the apoptotic pathway. ${ }^{26}$ The precise functions 
of DECAY and DAMM in programmed cell death in Drosophila are currently not well established.

Two proteins, Drosophila inhibitor of apoptosis 1 and 2 (DIAP1 and DIAP2) suppress programmed cell death in the fly eye induced by REAPER, HID or GRIM overexpression. ${ }^{29}$ Both DIAP1 and DIAP2 interact with REAPER, HID and GRIM. ${ }^{30,31}$ Loss of function mutations of diap1 suggest that this gene is required for the survival of cells. ${ }^{32,33}$ DIAP1 inhibits the activity of a number of Drosophila caspases including DCP-1, DRICE and DRONC, and has been shown to interact directly with DRICE and DRONC. ${ }^{18,26,34,35}$ Based on these results, it is proposed that REAPER, HID and GRIM mediate cell death by inhibiting DIAP1 function as a caspase inhibitor. ${ }^{36}$ While the role of DIAP1 is clearly required for cell survival, DIAP2 function is more puzzling. Although diap2 overexpression in the eye inhibits cell death by rpr, hid and grim overexpression, and DIAP2 can associate with REAPER, HID and GRIM proteins, the deficiencies removing the diap2 locus have no effect on rpr or hid-dependent apoptosis in the eye. ${ }^{29,36}$ Also, DIAP2 has not been shown to interact with any of the Drosophila caspases thus far. ${ }^{36}$

Here, we report cloning and initial characterisation of the Drosophila caspase, STRICA. STRICA contains an unusual and novel prodomain rich in Ser and Thr residues. We show that strica mRNA is widely expressed during development and overexpression of strica induces apoptosis in Drosophila SL2 cells. We also demonstrate that unlike other fly caspases, STRICA interacts with DIAP2.

\section{Results}

\section{Identification of STRICA}

While searching for new molecules with homology to various mammalian caspases using the TBLASTN program, we identified a genomic sequence contained in a database entry (accession no. AC014299) in the GenBank database which encoded a partial caspase-like molecule. Using a genomic PCR product, and with the help of an EST, we cloned the fulllength cDNA for this molecule. A comparison with the Drosophila genomic sequence in GenBank revealed that strica cDNA sequence is encoded by 3 exons (Figure 1A), which differs from the gene stucture predicted in the flybase. strica cDNA has an open-reading frame of 527 amino acid residues and the predicted protein shares significant homology with the mammalian caspases (Figure 1B,C). Analysis of the primary structure of this new caspase molecule revealed the presence of a long amino-terminal prodomain, rich in Ser and Thr residues. The prodomain sequence shares no homology with any of the other known caspase prodomains and lacks any CARD or DED-like motifs. This new molecule was named STRICA, for $\underline{\text { Ser/Thr-Rilch }}$ CAspase.

Based on amino acid sequence comparison with other known mammalian and insect caspases, STRICA is most homologous to the long prodomain-containing caspases DREDD, and caspase-8 (Figure 1C). Interestingly, the caspase domain of STRICA shares the highest degree of identity with the caspase DAMM (GenBank accession no.
AF240763). The QACKG sequence surrounding the catalytic Cys residue is identical in DAMM and STRICA. None of the other five fly caspases share this sequence.

\section{strica expression during Drosophila development}

Northern blot anyalysis of strica expression showed very weak bands of around $2.2 \mathrm{~kb}$ in several developmental stages (data not shown) suggesting that strica is expressed at low levels during development. RT-PCR analysis of strica revealed that strica is expressed at all stages of development, however, expression was somewhat lower in late larval stages and higher during pupation and in adult flies (Figure 2). The expression pattern of strica during fly development was further analyzed by in situ hybridisation to Drosophila embryos and larval tissues using a digoxigenin-labeled antisense mRNA probe (Figure 3). In early embryos, strica mRNA was present uniformally, but became more concentrated in some tissues later in embryogenesis (Figure $3 A-C$ ). strica expression was clearly evident in the midgut and salivary glands from third instar larvae (Figure 3E). These tissues are known to undergo massive cell death during larva to pupa metamorphosis and are completely removed during pupation. ${ }^{37}$ mRNA for other fly caspases, including dronc and decay, are known to accumulate in larval midgut and salivary gland before the histolysis of these tissues. ${ }^{11,12}$ Relatively high levels of strica transcript was evident in the nurse cell compartment of stage 10a and 10b ovaries (Figure 3I). At later stages, when nurse cells dump their cytoplasmic contents into the oocyte ${ }^{38}$ strica mRNA was clearly seen in the oocyte. These results indicate that the relatively high levels of strica RNA in early embryos (Figure 3A; data not shown for precellularised embryos) are likely to be derived maternally.

\section{STRICA localises to the cytoplasm in transfected cells}

To assess the cellular localisation of STRICA, cells were transiently transfected with expression constructs containing either the wild-type STRICA or STRICA with its catalytic Cys residue replaced with a Gly residue $\left(\mathrm{C}_{429} \mathrm{G}\right)$, both tagged at their carboxyl termini with the Flag epitope. Expression of Flag-tagged STRICA was then assessed by immunofluorescence using an anti-Flag monoclonal antibody. In both mammalian 293T cells and the Drosophila SL2 cells, STRICA protein was localised throughout the cytoplasm, completely exclusive of the nucleus (Figure 4). In 293T cells, STRICA appeared to be localised to the cytoskeleton, however, costaining with actin suggested that STRICA does not colocalise with actin fibres (data not shown).

\section{STRICA does not dimerise in yeast two-hybrid assays}

Caspases with long prodomains are believed to be activated by a proximity-induced autocatalytic process. ${ }^{13,14}$ In this model, CARDs or DEDs in the prodomains mediate oligomerisation of the procaspase molecules directly, or via specific adaptor molecules. In the case of mammalian caspase-2, the CARD region in the prodomain is sufficient 
A

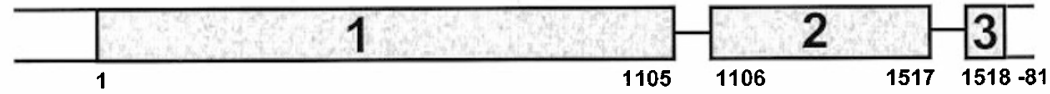

B

MGWWSKKSETDRSQPSQELVAQDPRTRVQTTSAATETINTAVQNSTITDN

NKQTVTFLTTRQTVTHTQRALITETTTRRTPSQAELEALFAKIKMGGEGP

100

IGSTTTTTTTTSSRSRPPSLNGVSFRSTQPFKATASNAGKRSSTLVKTEQ

TTVTQKNGRTVTQHLETHRVDLKGSRPKATWASFASTANSSTSSYVSPYR QKPSMAITCTSPNIKTPKTTSSTSSSSASSITSPPKPSSSVSSISSIFKS APKQVDKPLSSTATPKPFISLGSSGGTKPKVTAVAQSQDAQGTISTSLGI

C

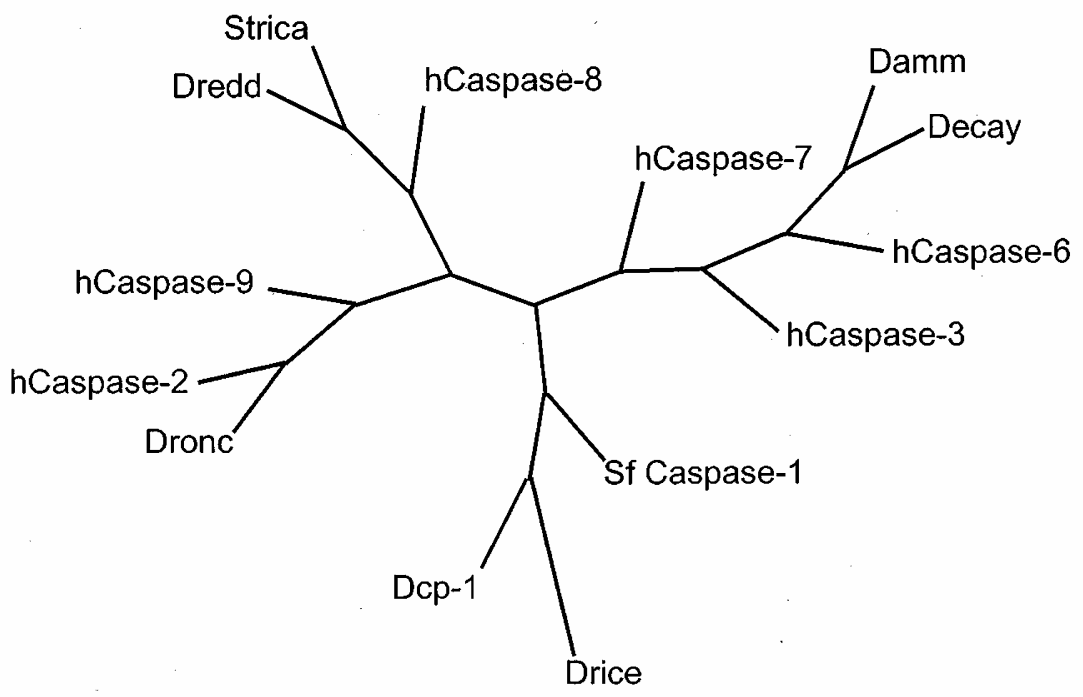

Figure 1 (A) The genomic organisation of the strica gene is shown. The gene consists of three exons separated by two small intronic sequences. Numbers denote the coding region of the gene. The 5'- and 3'-most exon boundaries are not known. (B) The primary sequence of the STRICA protein is shown, with the catalytic Cys and surrounding residues highlighted in black. The putative prodomain region of STRICA is rich in Ser and Thr residues as highlighted in grey. (C) A phylogenetic tree of relationships between the Drosophila caspase family members and various mammalian caspases. The sequences for various caspases were derived from the GenBank database

for homodimerisation in yeast two-hybrid assays. ${ }^{39,40}$ Although the long prodomain of STRICA bears no similarity to any other known sequence in the database, we were interested to test whether the prodomain has the ability to homodimerise in yeast two-hybrid assays. Various STRICA constructs were generated in the yeast two-hybrid vectors pAS2.1 and pACT2. Pairs of constructs were simultaneously transformed into yeast strain $\mathrm{Hf7C}$ and plated onto medium lacking Trp and Leu to select for yeast colonies expressing both plasmids. To select for colonies expressing proteins capable of interaction, the same transformation was plated onto medium lacking Trp/Leu/His. All STRICA transformants were able to grow on -Leu/-Trp medium demonstrating that these cells were expressing both constructs, however no growth was observed on -Leu/-Trp/-His plates (Table 1). Under similar conditions, two controls including murine p53/ SV40 Large $T$ antigen, and the caspase-2 prodomain were able to grow on both plates, as expected. These results suggest that, unlike the caspase-2 prodomain, the STRICA prodomain does not have the ability to homodimerise. 


\section{Ectopic expression of STRICA induces apoptosis in SL2 cells}

Many caspases, when overexpressed in cultured cells, induce apoptosis to some degree. ${ }^{1-4}$ We therefore analyzed whether STRICA is able to induce apoptosis in transfected cells. We expressed strica in Drosophila SL2 cells from a copper-inducible insect promoter. At $48 \mathrm{~h}$ following induction of protein expression, around $50 \%$ of cells transfected with the wild-type strica construct were lost when compared to cells transfected with vector alone (Figure 5). An expression construct carrying a substitution mutant of the putative catalytic Cys $\left(\mathrm{C}_{429} \mathrm{G}\right)$ residue of STRICA was unable to induce cell death suggesting that the caspase activity of STRICA was responsible for its apoptosis-inducing ability (Figure 5). STRICA-induced apoptosis in SL2 cells was

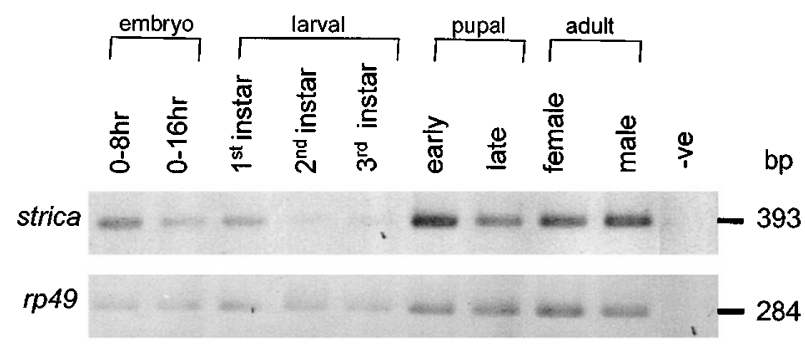

Figure 2 strica mRNA is expressed throughout Drosophila development cDNA synthesised from total RNA was used as a template for PCR. The expected $393 \mathrm{bp}$ strica product was detected in all stages of development. Expression is somewhat lower in late larval stages, before being upregulated in pupal stages and maintained in the adult. Drosophila ribosomal protein 49 (rp49) expressed ubiquitously throughout Drosophila development was used as an internal control. strica and rp49 cDNA amplification was carried out simultaneously using appropriate primers in each individual reaction significantly inhibited by DIAP1. However, DIAP2 and the baculovirus apoptosis inhibitor P35 did not appear to significantly affect STRICA-induced apoptosis in this assay system (Figure 5).
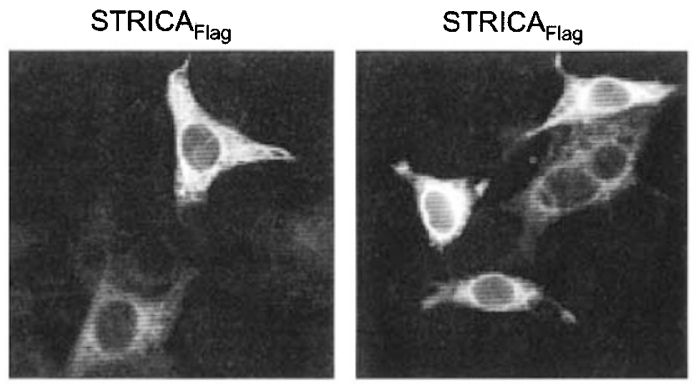

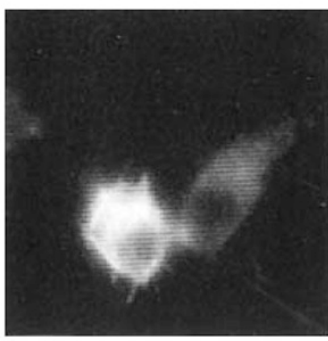

$\operatorname{STRICA}\left(\mathrm{C}_{429} \mathrm{G}\right)_{\text {Flag }}$

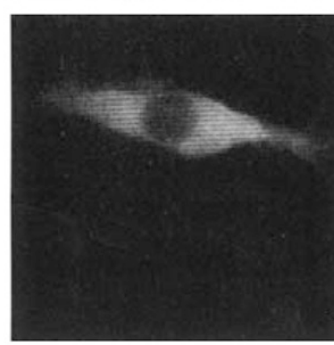

STRICA Flag
Figure 4 Localisation of STRICA protein in transfected cells. Flag-tagged STRICA or STRICA $\left(\mathrm{C}_{429} \mathrm{G}\right)$ expression constructs were transfected into 293T cells (upper panels) and Drosophila SL2 cells (lower panels). For 293T cells, $24 \mathrm{~h}$ post-transfection, cells were fixed and stained with Flag antibody and analyzed by fluorescence microscopy. For SL2 cells, STRICA expression was induced by addition of $\mathrm{CuSO}_{4}$ for $24 \mathrm{~h}$ prior to fixation, immunostaining and visualisation. In both cell types, STRICA expression is predominantly cytoplasmic
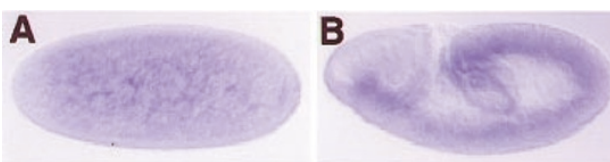

E
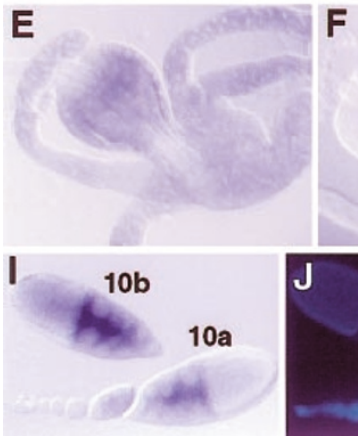

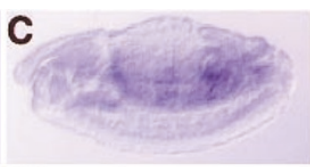

G

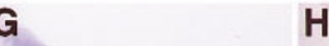

H
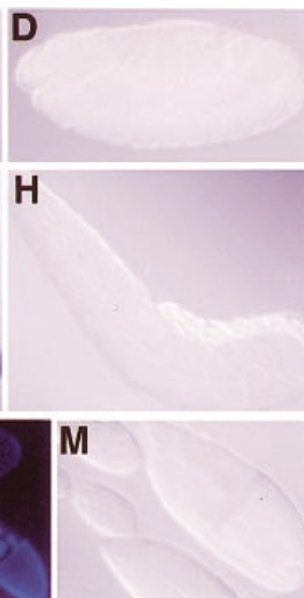

Figure 3 In situ analysis of strica expression during development. A strica antisense RNA probe labelled with digoxygenin was used to detect expression in situ. (A) Expression of strica in a stage 4 syncytial blastoderm shows remnants of maternally deposited mRNA. (B,C) Germ band extended (stage $9-10)$ and germ band retracted (stage 13-14) with antisense strica probe. (D) Germ band retracted (stage 13-14) with sense control strica probe. Late 3rd instar larval midgut with antisense strica probe, $(\mathbf{E})$ and negative control sense probe (F). Late 3rd instar larval salivary glands with antisense strica $(\mathbf{G})$ and sense control probe (H). Adult ovaries (stage 10a and 10b) with sense strica probe (I) and stained with Hoechst DNA stain (J). Adult ovaries before (stage 10a) and after (stage 11/12) nurse cell cytoplasmic dumping (K). (L) Hoeschst staining of the ovaries shown in (K). (M) Adult ovaries stained with sense strica probe 
Table 1 The prodomain of STRICA is not a dimerisation domain. Various STRICA constructs were expressed in the yeast two-hybrid vectors pAS2.1, which carries a TRP1 nutritional marker gene, and pACT2, which carries a LEU2 marker gene. Hf7C competent yeast cells were transformed with pairs of constructs and plated onto selection medium. Positive interactors were able to grow on medium lacking His

\begin{tabular}{lll}
\hline $\begin{array}{l}\text { Gal4BD construct in } \\
\text { vector pAS2.1 }\end{array}$ & $\begin{array}{l}\text { Gal4AD construct in } \\
\text { vector pACT2 }\end{array}$ & $\begin{array}{c}\text { Growth on } \\
\text { LEU-TRP }\end{array}$ \\
\hline Empty vector & Empty vector & + \\
Caspase-2 prodomain & Caspase-2 prodomain & + \\
p53 & SV40 Large T antigen & + \\
p53 & Empty vector & + \\
STRICA $\left(\mathrm{C}_{429} \mathrm{G}\right)$ & STRICA (C $\left.{ }_{429} \mathrm{G}\right)$ & + \\
STRICA $\left(\mathrm{C}_{429} \mathrm{G}\right)$ & STRICA MPD & + \\
STRICA (C $429 \mathrm{G})$ & STRICA prodomain & + \\
STRICA prodomain & STRICA prodomain & + \\
\hline
\end{tabular}

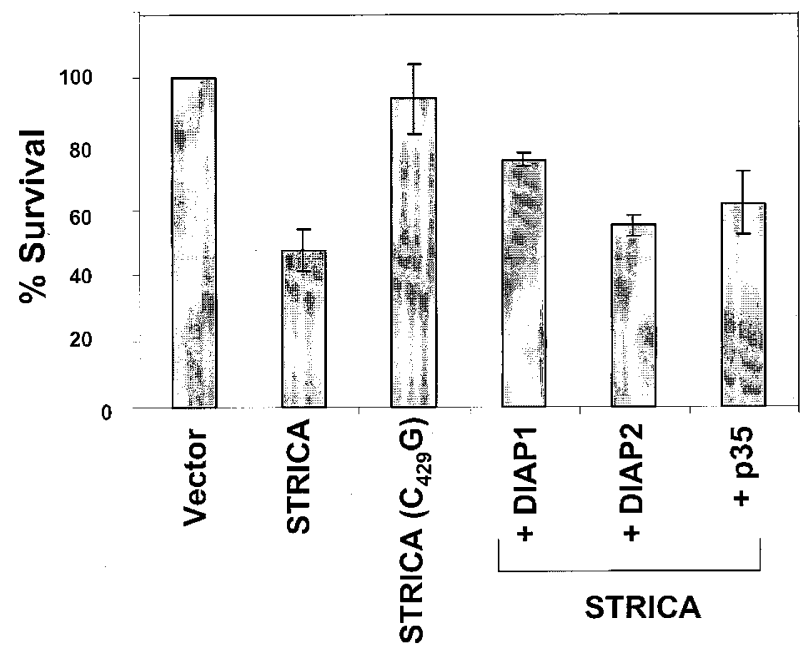

Figure 5 Overexpression of STRICA in cultured SL2 cells induces cell death Drosophila SL2 cells were cotransfected with either $2 \mu \mathrm{g}$ empty pRmHa3 vector, $1 \mu \mathrm{g}$ pRmHa3-strica $+1 \mu \mathrm{g}$ empty pRmHa3, or $1 \mu \mathrm{g} \mathrm{pRmHa} 3$-strica $\left(C_{429} \mathrm{G}\right)+1 \mu \mathrm{g}$ empty $\mathrm{pRmHa} 3$, and $0.5 \mu \mathrm{g} \mathrm{pCaSpeR}-\beta \mathrm{gal}$ expression constructs. Expression was induced $24 \mathrm{~h}$ post-transfection by the addition of $\mathrm{CuSO}_{4}$ to a final concentration of $0.7 \mathrm{mM}$. Loss of cells was determined $48 \mathrm{~h}$ post-induction by the ratio of blue cells in copper-induced transfectants to the number of blue cells in uninduced cells. A minimum of 200 cells were counted in each of three duplicate experiments. Where indicated, STRICA expression constructs were cotransfected in equal amounts with DIAP1, DIAP2 and p35 expression constructs in pRmHa3. Wild-type STRICA expression resulted in approximately $50 \%$ loss of cells, whereas the Cys mutant did not induce significant apoptosis

\section{STRICA interacts with with DIAP1 and DIAP2}

Recent data suggest that DIAP1, but not DIAP2, is able to interact with a number of Drosophila caspases including DRONC, DCP-1 and DRICE. ${ }^{18,26,34-36}$ To determine whether STRICA is capable of such interaction, cells were cotransfected with STRICA, or STRICA lacking the prodomain (STRICA-MPD), and DIAP1 or DIAP2. Cell lysates were immunoprecipitated and immuno-complexes analyzed by immunoblotting. DRONC, that has been shown to interact with DIAP1, but not DIAP2, in a prodomain-dependent manner, ${ }^{26}$ was used as a positive control. As expected, DRONC was coprecipitated with DIAP1. Full-length STRICA coprecipitated with both DIAP1 and DIAP2 (Figure 6). Interestingly, STRICA-MPD was still able to interact with both DIAP1 and DIAP2, suggesting that the prodomain of
STRICA is not required for interaction with these inhibitors. We also tested whether STRICA and the baculovirus caspase inhibitor P35 can interact. However, in cotransfection experiments, no interaction between P35 and STRICA could be seen (data not shown).

\section{Discussion}

Here, we have reported the identification and preliminary characterisation of the newest member of the Drosophila family of caspases, STRICA. STRICA was identified by a database homology search, and cloned from a Drosophila larval cDNA library. The resulting 527 amino acid polypeptide contains all the residues conserved throughout the caspase superfamily as well as a long amino-terminal prodomain rich in serine and threonine residues. Although the role of this novel prodomain is not well elucidated, it is clearly not required for oligomerisation of STRICA procaspase molecules, and does not mediate interaction with the Drosophila inhibitors of apoptosis, DIAP1 and DIAP2. Given the lack of homology of this domain to other known prodomains which contain various protein - protein interaction motifs, the role of the prodomain of STRICA is an interesting point for further investigation, which may reveal novel mechanisms of caspase activation and regulation. STRICA is expressed throughout Drosophila development at relatively low levels, and is seen in tissues which are known to undergo developmental apoptosis. STRICA localises to the cytoplasm of transfected cells. Although STRICA induces cell death when overexpressed in SL2 cells, the in vivo role of STRICA in apoptosis requires further investigation.

STRICA interacts with DIAP1, the role of which has been well defined in the apoptotic pathway. Interestingly, although DIAP2 does not significantly inhibit STRICAinduced apoptosis, interaction between these two proteins was clearly evident in transfected cells. The function of DIAP2 is less clear than that of DIAP1. Unlike DIAP1, DIAP2 has not been shown to interact with any other known caspases thus far. ${ }^{36}$ The physiological relevance of the interaction between DIAP2 and STRICA is not known, however the lack of inhibition of STRICA-induced cell death by DIAP2 may indicate an involvement of STRICA and DIAP2 in a non-apoptotic cellular pathway.

So far we have not been able to test the biochemical activity of STRICA. Recombinant STRICA produced in E. coli does not show any activity on commercially available 


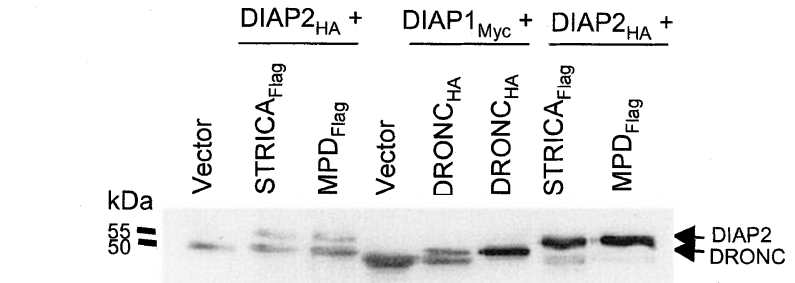

WB: $\alpha H A$

IP:
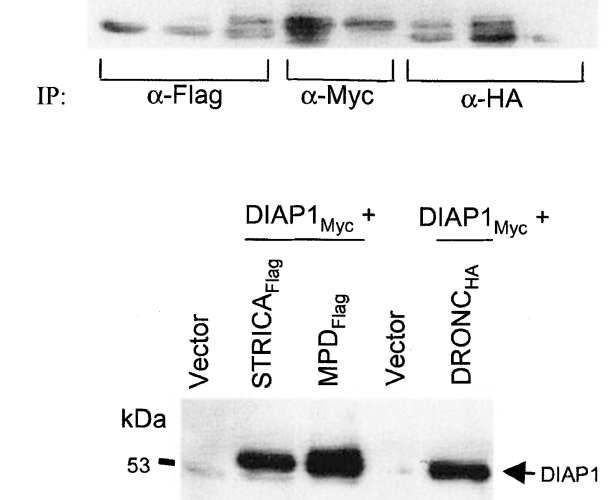

WB: $\alpha M y c$
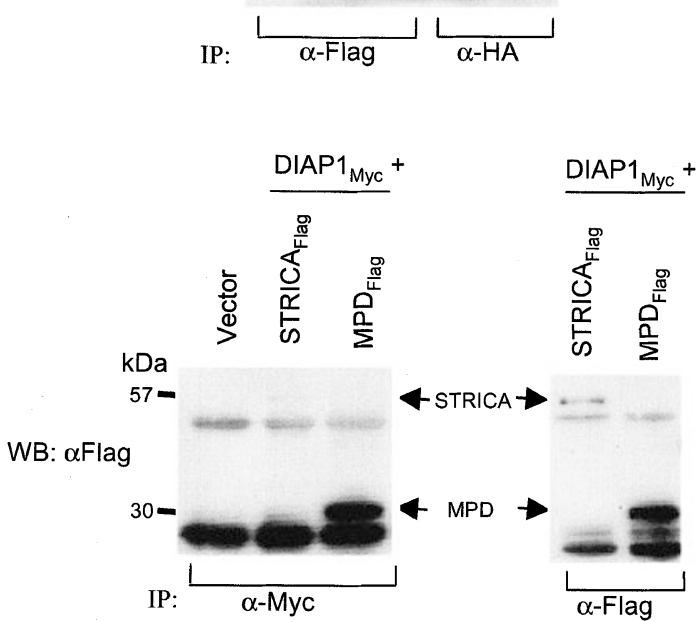

Figure 6 STRICA interacts with DIAP1 and DIAP2. 293T cells were cotransfected with various tagged cDNAs in pcDNA3 expression vector. Two $\mu \mathrm{g}$ of Flag-tagged STRICA or STRICA lacking the prodomain (MPD) were cotransfected with $2 \mu \mathrm{g}$ of either Myc-tagged DIAP1 or HA-tagged DIAP2. Forty-eight hours after transfection, cells were harvested and lysed. Both DIAP1 and DIAP2 were detected in lysates immunoprecipitated with an antiFlag antibody. STRICA and STRICA-MPD were detected in lysates immunoprecipitated with anti-Myc, but not with anti-HA (data not shown). In a control experiment, HA-tagged DRONC coimmunopreciptated with DIAP1, as expected. Expression of each construct was confirmed by immunoprecipitating with the appropriate antibody, followed by immunoblotting with the same antibody. All STRICA constructs used in these experiments contained the C429G mutation

caspase substrates, including YVAD, DEVD, VDVAD, VEID and LHTD (data not shown). This suggests that either recombinant STRICA is not catalytically active, or that STRICA has a substrate specificity that is substantially different from other caspases and not represented by the caspase substrates we have tested so far. We have also not detected processing of STRICA by other caspases (data not shown). Thus, the requirement for procaspase processing for STRICA activation is yet to be fully understood.

We have been unable to detect processing of STRICA in transiently transfected insect cells exposed to apoptotic stimuli (data not shown). This apparent lack of STRICA processing in apoptotic cells may suggest a role for this caspase in pathways additional to and/or outside of apoptosis. DIAP1 and DIAP2 have been shown to interact with Thick Veins, a Ser/Thr kinase receptor for Decapentaplegic (DPP), a Drosophila TGF- family member. ${ }^{41}$ It may be that both STRICA and DIAP2 function in the DPP signalling pathway. To explore this possibility further, it will be necessary to identify other binding partners for STRICA and to generate and analyze the STRICA mutant phenotype. There are several potential Ser/Thr phosphorylation sites in the STRICA prodomain, which may mediate the binding of STRICA to other signalling molecules.

\section{Materials and Methods}

\section{Cloning of strica cDNA and homology analysis}

strica was identified using a TBLASTN search of the Berkeley Drosophila Genome Project database, as a region of genomic DNA sequence displaying significant homology to mammalian caspases. From this region of homology, strica-specific primers were designed and were used in conjunction with library-specific vector primers to amplify the partial open reading frame of strica from a Drosophila larval cDNA library. The $5^{\prime}$ end of the strica open reading frame was obtained from EST clone LP09213 (Research Genetics). The cDNA sequence of strica has been deposited in the GenBank database under accession number AF242735. Multiple sequence alignments and construction of phylogenetic trees were carried out using Bionavigator software packages ClustalW and Protpars at the Australian National Genome Information Services server.

\section{Plasmid constructs}

A 393 bp sequence, from residue 1108 to residue 1500, spanning the active site-encoding sequence of strica was amplified by PCR using Taq DNA Polymerase (Perkin Elmer), and cloned by overhanging $T$ bases into pGEM ${ }^{\mathbb{R}}$-T Easy (Promega) and sequenced. The $965 \mathrm{bp}$ of the strica open reading frame starting from position 612 to the $3^{\prime}$ end was amplified from a Drosophila larval cDNA library and cloned directionally into pcDNA3 vector (Invitrogen) using the following nucleotides: Primer A 5 '-GCCGGTACCATGGCCATAACTTGCACATCTCCC and primer B 5'-CGCTCTAGATCACTTGTCATCGTCCTTGAATATAATCTCCAAAAAGG. Primer B contained an Xbal restriction site (italicised) and a Flag tag-encoding sequence (underlined). Eight hundred and thirty-four bp of the $5^{\prime}$-most region of strica was amplified from an EST clone (LP09213) encoding an incomplete strica/ transferrin precursor fusion and was directionally cloned into pcDNA3 using the following primers: Primer $C$ 5'-GCCGGTACCATGGGTTGGTGGAGCAAGAAAGCG and Primer D 5'CTTGGTGCCTCCTGACGATCC. Full-length strica was obtained by a 3-way cloning step using an internal Banl restriction site in the region 
overlapping between each incomplete pcDNA3 clone. The resulting

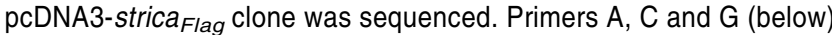
contained $K p n l$ restriction sites (italicised). The putative catalytic Cys429 residue of STRICA was mutated to a Gly residue by Quikchange mutagenesis (Stratagene) using pcDNA3-strica Flag $_{\text {as a }}$ template. strica ${ }_{\text {Flag }}$ and strica $\left(C_{429} G\right)_{\text {Flag }}$ were amplified from pcDNA3-strica $_{\text {Flag }}$ and pcDNA3-strica $\left(C_{429} G\right)_{\text {Flag }}$ using Pwo DNA polymerase (Roche Biochemicals) using primers $B$ and $C$ and cloned into insect vector pRmHa.3. ${ }^{42}$ Minus prodomain (MPD) constructs were made by amplifying strica using Primer B and Primer G: 5'GGCGGTACCATGGCGAAGCCGCTCAGTTCTACCGC, and cloning into pcDNA3.

Apoptosis inhibitors diap1, diap2 and p35 were amplified using $P$ wo polymerase (Roche Biochemicals) and the following primers: DIAP1A 5'-CGGAATTCATGGCATCTGTTGTAGCTGATC, DIAP1B 5'CGCGGATCCGCGTCATGCGTAGTCTGGCACGTCGTATGGGTAAGAAAAATATACGCGCATC, DIAP2A 5'-CGGAATTCATGACGGAGCTGGGCATG, DIAP2B 5'-CGCGGATCCGCGTCATGCGTGGCACGTCGTATGGGTAATCGATTTG-CTTAACTGC, P35A 5'CGGAATTCATGTGTGTAATTTTTCCG, P35B 5'-CGCGGATCCGCGTCATGCGTAGTCTGGCACGTCGTATGGGTATTTAATTTAC. In each case the forward primers contained an EcoRI site (in italics), while the reverse primers contained a BamHI site (in italics) and sequence encoding an $\mathrm{HA}$ tag (underlined). diap1HA, diap2 $\mathrm{HA}$ and $p 35 \mathrm{HA}$ were cloned into $\mathrm{pRmHa} .3^{42}$ for expression in insect cells and into pcDNA3 for expression in mammalian cells.

\section{In situ mRNA expression analysis}

For in situ RNA analysis, antisense and sense digoxygenin labelled riboprobes were prepared using T7 and SP6 RNA polymerases from a linearized $p G E M{ }^{\mathbb{R}}-T$ Easy-strica clone containing a 393 bp fragment of strica cDNA. Digoxygenin labelling was performed according to the manufacturer's instructions (Roche Biochemicals). In situ hybridisation to Drosophila embryos and larval tissues were essentially as described. ${ }^{11,43}$

\section{Reverse transcriptase PCR}

Total RNA was prepared from each Drosophila developmental stage from early embryo to adult fly using TRIzol reagent (Life Technologies) as per the manufacturer's instructions. Random-primed cDNA was synthesised from $5 \mu \mathrm{g}$ total RNA using 1st strand cDNA synthesis kit (Amersham Pharmacia). One $\mu \mathrm{l}$ from each $33-\mu \mathrm{l}$ reaction was used as a template in a PCR reaction using the following primers: Primer $E 5^{\prime}$ CAAACCAAGGACTTTGAGGAC and Primer $F$ 5'-CACTTGACGCACATTCAT. As a positive control, a region spanning from bp 196 to bp 480 of the Drosophila ribosomal protein 49 (rp49) gene was amplified. Products were separated by agarose gel electrophoresis, stained with ethidium bromide, and scanned using a fluorimager.

\section{Immunofluorescence}

SL2 cells and 293T cells were seeded into $35-\mathrm{mm}$ dishes and transfected as described. ${ }^{12,43}$ Twenty-four hours post-transfection, cells were washed once in PBS and fixed in 4\% paraformaldehyde/ $0.18 \%$ Triton X-100 in PBS. Cells were washed and incubated with anti-Flag monoclonal antibody (SIGMA Chemical Co). Cells were then incubated in anti-mouse-FITC and mounted beneath coverslips in $80 \%$ glycerol. STRICA expression was visualised by fluorescence microscopy.

\section{Apoptosis assays}

Cell death assays in insect cells were carried out using Schneider L2 (SL2) cells. SL2 cells were maintained and transfected using Cellfectin (Life Technology) as described. ${ }^{43}$ For death assays, $1.5 \times 10^{6}$ SL2 cells were cotransfected with either $2 \mu \mathrm{g}$ vector or $1 \mu \mathrm{g} \mathrm{pRM-strica}{ }_{\text {Flag }}$ together with $1 \mu \mathrm{g}$ of respective pRmHa.3 inhibitor constructs, pRMdiap1 $1_{\mathrm{HA}}$, pRMdiap2 ${ }_{\mathrm{HA}}$ or pRMp35 $5_{\mathrm{HA}}$ and $0.5 \mu \mathrm{g}$ pCaSpeR- $\beta \mathrm{gal}$ reporter. ${ }^{44}$ All death assays were performed in duplicate. Twenty-four hours post transfection, cells were induced to express $\mathrm{pCaSpeR}-\beta \mathrm{gal}$ by three cycles of heat shock at $37^{\circ} \mathrm{C}$ for $30 \mathrm{~min}$ followed by $27^{\circ} \mathrm{C}$ for $30 \mathrm{~min}$. Following heat shock, one sample of each duplicate transfection was induced to express the respective pRmHa.3 constructs by the addition of $\mathrm{CuSO}_{4}$ at a final concentration of $0.7 \mathrm{mM}$. Cells were fixed and stained with X-gal $48 \mathrm{~h}$ post-CuSO${ }_{4}$ induction as previously described. ${ }^{45}$ Cell survival was calculated as the percentage of transfected ( $\beta$-galactosidase positive) cells in the $\mathrm{CuSO}_{4}$ treated population relative to the percentage of transfected cells in the untreated population. All calculations were normalised against the $100 \%$ survival value of vector-transfected cells. The results, shown as average percentages \pm S.E.M., were derived from three independent experiments. To check copper-induced protein expression after $48 \mathrm{~h}$ of $\mathrm{CuSO}_{4}$ treatment, cells were lysed in SDS-PAGE buffer and lysates were subjected to immunoblotting using an $\alpha \mathrm{HA}$ antibody (Roche Molecular Biologicals) or $\alpha$ Flag antibody (Sigma Chemical Co.).

\section{STRICA interaction studies}

293T cells were transfected using FuGene (Boehringer Mannheim). Two $\mu \mathrm{g}$ of pcDNA3-strica $\left(C_{429} G\right)_{\text {Flag }}$ or pcDNA3-strica $\left(C_{429} G\right) M P D_{\text {Flag }}$ were cotransfected with either $2 \mu \mathrm{g}$ pcDNA3 vector or $2 \mu \mathrm{g}$ of pcDNA3-diap $1_{m y c}$, pcDNA3-diap2 ${ }_{H A}$ or pcDNA3-p35 $5_{H A}$. As a positive control, pcDNA3-dronc ${ }_{H A}$ was cotransfected with pcDNA3diap1 $1_{\text {myc }}$. Twenty-four hours post transfection, cell lysates were prepared in lysis buffer $(20 \mathrm{mM} \mathrm{NaCl}, 0.2 \%$ Triton X-100, $10 \%$ glycerol, $20 \mathrm{mM}$ Tris- $\mathrm{HCl} \mathrm{pH} 7.5$, supplemented with a $1 \times$ protease inhibitor cocktail (Complete ${ }^{\mathrm{TM}}$, Roche) Lysates were immunoprecipitated with $2 \mu \mathrm{g}$ of either $\alpha$ Flag M2 (Sigma Chemical Co.), $\alpha \mathrm{HA} 11$ (Roche) or $\alpha \mathrm{Myc}$ (Roche). Immunoprecipitated protein was separated by SDSPAGE and analyzed by immunoblotting using the appropriate anitbodies.

\section{Acknowledgements}

We thank Natasha Harvey and Loretta Dorstyn for sharing reagents and for helpful comments. This work was supported by the Wellcome Trust and the National Health and Medical Council of Australia. S Kumar and $\mathrm{H}$ Richardson are Wellcome Senior Fellows in Medical Science. $\mathrm{J}$ Doumanis is a Dawes Postgraduate Scholar.

\section{References}

1. Kumar S and Lavin MF (1996) The ICE family of cysteine proteases as effectors of cell death. Cell Death Differ. 3: 255-267

2. Thornberry NA and Lazebnik Y (1998) Caspases: enemies within. Science 281: $312-316$

3. Kumar S (1995) ICE-like proteases in apoptosis. Trends Biochem. Sci. 20: 198202

4. Nicholson DW (1999) Caspase structure, proteolytic substrates, and function during apoptotic cell death. Cell Death Differ. 6: 1028-1042

5. Kumar S and Doumanis J (2000) The fly caspases. Cell Death Differ. 7: 1039 1044 
6. Zheng TS, Hunot S, Kuida K and Flavell RA (1999) Caspase knockouts: matters of life and death. Cell Death Differ. 6: 1043-1053

7. Song Z, McCall K and Steller H (1997) DCP-1, a Drosophila cell death protease essential for development. Science 275: 536-540

8. Fraser AG and Evan GI (1997) Identification of a Drosophila melanogaster ICE/ CED-3-related protease, drICE. EMBO J. 16: 2805-2813

9. Chen P, Rodriguez A, Erskine R, Thach T and Abrams JM (1998) Dredd, a novel effector of the apoptosis activators reaper, grim, and hid in Drosophila. Dev. Biol. 201: $202-216$

10. Inohara N, Koseki T, Hu Y, Chen S and Núñez G (1997) CLARP, a death effector domain containing protein interacts with caspase-8 and regulates apoptosis. Proc. Natl. Acad. Sci. USA 94: 10717-10722

11. Dorstyn L, Colussi PA, Quinn LM, Richardson Hand Kumar S (1999) DRONC, an ecdysone inducible Drosophila caspase. Proc. Natl. Acad. Sci. USA 96: 4307 4312

12. Dorstyn L, Read SH, Quinn LM, Richardson H and Kumar S (1999) DECAY, a novel Drosophila caspase related to mammalian caspase-3 and caspase-7. J. Biol. Chem. 274: 30778-30783

13. Kumar S (1999) Mechanisms mediating caspase activation in apoptosis. Cell Death Differ. 6: 1060-1066

14. Kumar S and Colussi PA (1999) Prodomains-adaptors-oligomerization: the pursuit of caspase activation in apoptosis. Trends Biochem. Sci. 24: 1-4

15. Li P, Nijhawan D, Budihardjo I, Srinivasula SM, Ahmad M, Alnemri ES and Wang X (1997) Cytochrome $c$ and dATP-dependent formation of Apaf-1/caspase-9 complex initiates an apoptotic protease cascade. Cell 91: 479-489

16. Zou H, Li Y, Liu X and Wang X (1999) An APAF-1-cytochrome c multimeric complex is a functional apoptosome that activates procaspase-9. J. Biol. Chem. 274: $11549-11556$

17. Aravind L, Dixit VM and Koonin EV (1999) The domains of death: evolution of apoptosis machinery. Trends Biochem. Sci. 24: 47-53

18. Quinn LM, Dorstyn L, Mills K, Colussi PA, Chen P, Coombe M, Abrams J, Kumar $S$ and Richardson $\mathrm{H}$ (2000) An essential role for the caspase Dronc in developmentally programmed cell death in Drosophila. J. Biol. Chem. 275: 40416-40424

19. Rodriguez A, Oliver H, Zou H, Chen P, Wang X and Abrams JM (1999) Dark is a Drosophila homologue of Apaf-1/CED-4 and functions in an evolutionarily conserved death pathway. Nat. Cell Biol. 1:272-279

20. Kanuka H, Sawamoto K, Inohara N, Matsuno K, Okano H and Miura M (1999) Control of the cell death pathway by Dapaf-1, a Drosophila Apaf-1/CED-4-related caspase activator. Mol. Cell 4: 757-769

21. Hu S and Yang X (2000) dFADD, a novel death domain-containing adaptor protein for the Drosophila caspase DREDD. J. Biol. Chem. 275: 30761-30764

22. McCall K and Steller H (1998) Requirement for DCP-1 caspase during Drosophila oogenesis. Science 279: 230-234

23. Leulier F, Rodriguez A, Khush RS, Abrams JM and Lemaitre B (2000) The Drosophila caspase Dredd is required to resist Gram-negative bacteria infection. EMBO Rep. 1: 353-358

24. Elrod-Erickson M, Mishra S and Schneider D (2000) Interactions between the cellular and humoral responses in Drosophila. Curr. Biol. 10: 781-784

25. Stöven S, Ando I, Kadalayil L, Engström Y and Hultmark D (2000) Activation of the Drosophila NF- $\kappa$ B factor Relish by rapid endoproteolytic cleavage. EMBO Rep. 1: 347-352

26. Meier P, Silke J, Leevers SJ and Evan GI (2000) The Drosophila caspase DRONC is regulated by DIAP1. EMBO J. 19: 598-611
27. Hawkins CJ, Yoo SJ, Peterson EP, Wang SL, Vernooy SY and Hay BA (2000) The Drosophila caspase DRONC is a glutamate/aspartate protease whose activity is regulated by DIAP1, HID and GRIM. J. Biol. Chem. 275: 27084-27093

28. Fraser AG, McCarthy NJ and Evan Gl (1997) drICE is an essential caspase required for apoptotic activity in Drosophila cells. EMBO J. 16: 6192-6199

29. Hay BA, Wassarman DA and Rubin GM. (1995) Drosophila homologs of baculovirus inhibitor of apoptosis proteins function to block cell death. Cell 83 : $1253-1262$

30. Vucic D, Kaiser WJ, Harvey AJ and Miller LK (1997) Inhibition of Reaper-induced apoptosis by interaction with inhibitor of apoptosis proteins (IAPs). Proc. Natl. Acad. Sci. USA 94: 10183-10188

31. Vucic D, Kaiser WJ and Miller LK (1998) Inhibitor of apoptosis proteins physically interact with and block apoptosis induced by Drosophila proteins HID and GRIM. Mol. Cell. Biol. 18: 3300-3309

32. Wang SL, Hawkins CJ, Yoo SJ, Muller HA and Hay BA (1999) The Drosophila caspase inhibitor DIAP1 is essential for cell survival and is negatively regulated by HID. Cell $98: 453-463$

33. Goyal L, McCall K, Agapite J, Hartwieg E and Steller H (2000) Induction of apoptosis by Drosophila reaper, hid and grim through inhibition of IAP function. EMBO J. 19: 589-597

34. Hawkins CJ, Wang SL and Hay BA (1999) A cloning method to identify caspases and their regulators in yeast: Identification of Drosophila IAP1 as an inhibitor of the Drosophila caspase DCP-1. Proc. Natl. Acad. Sci. USA 96: 2885-2890

35. Kaiser WJ, Vucic D and Miller LK (1998) The Drosophila inhibitor of apoptosis DIAP1 suppresses cell death induced by the caspase drICE. FEBS Lett. 440: $243-248$

36. Hay BA (2000) Understanding IAP function and regulation: a view from Drosophila. Cell Death Differ. 7: 1045-1056

37. Baehrecke EH (2000) Steroid regulation of programmed cell death during Drosophila development. Cell Death Differ. 7: 1057-1062

38. Buszczak M and Cooley L (2000) Eggs to die for: cell death during Drosophila oogenesis. Cell Death Differ. 7: 1071-1074

39. Butt AJ, Harvey NL, Parasivam G and Kumar S (1998) Dimerization and autoprocessing of the Nedd2 (Caspase-2) precursor requires both the prodomain and the carboxyl-terminal regions. J. Biol. Chem. 273: 6763-6768

40. Colussi PA, Harvey NL, Shearwin-Whyatt LM and Kumar S (1998) Conversion of procaspase- 3 to an autoactivating caspase by fusion to the caspase-2 prodomain. J. Biol. Chem. 273: 26566-26570

41. OedaE, Oka Y, Miyazono Kand Kawabata M (1998) Interaction of the Drosophila inhibitors of apoptosis with Thick Veins, a type I serine/threonine kinase receptor for Decapentaplegic. J. Biol. Chem. 273: 9353-9356

42. Bunch TA, Grinblat $Y$ and Goldstein LS (1998) Characterization and use of the Drosophila metallothionein promoter in cultured Drosophila melanogastercells. Nucleic Acids. Res. 16: 1043-1061

43. Colussi PA, Quinn LM, Huang DCS, Coombe M, Read, SH, Richardson H and Kumar S (2000) Debcl, a proapoptotic Bcl-2 homologue, is a component of the Drosophila melanogaster cell death machinery. J. Cell Biol. 148: 703-714

44. Thummel CS and Pirrotta V (1991) Technical notes: New pCaSpeR P-element vectors. Drosophila Information Newsletter Volume 2.

45. Kumar S, Kinoshita M, Noda M, Copeland NG and Jenkins NA (1994) Induction of apoptosis by the mouse Nedd2 gene, which encodes a protein similar to the product of the Caenorhabiditis elegans cell death gene ced-3 and the mammalian IL-1 beta-converting enzyme. Genes Dev. 8: 1613-1626 